\title{
Innate Immune System and Inflammation in Alzheimer's Disease: From Pathogenesis to Treatment
}

\author{
Maria Serpente Rossana Bonsi Elio Scarpini Daniela Galimberti \\ Neurology Unit, Department of Pathophysiology and Transplantation, University of Milan, Fondazione Cà Granda, \\ IRCCS Ospedale Maggiore Policlinico, Milan, Italy
}

\section{Key Words}

Alzheimer's disease · Inflammation · Microglia · Immune system · Vaccination · Immunization · Cytokines

\begin{abstract}
Immune activation and inflammation, likely triggered by amyloid-beta $(A \beta)$ deposition, play a remarkable role in the pathogenesis of Alzheimer's disease (AD), which is the most frequent cause of dementia in the elderly. The principal cellular elements of the brain innate immune system likely to be involved in such processes are microglia. In an attempt to search for new disease-modifying drugs, the immune system has been addressed, with the aim of removing deposition of $A \beta$ or tau by developing vaccines and humanized monoclonal antibodies. The aim of this review is to summarize the current evidence regarding the role played by microglia and inflammatory molecules in the pathogenesis of AD. In addition, we will discuss the main active and passive immunotherapeutic approaches.
\end{abstract}

(c) 2014 S. Karger AG, Basel

\section{Introduction}

Alzheimer's disease (AD) is the most common form of neurodegenerative disease, which leads to a progressive loss of memory and cognitive functions. The neu-

\section{KARGER}

E-Mail karger@karger.com

www.karger.com/nim ropathological hallmarks of $\mathrm{AD}$ include neurofibrillary tangles formed by accumulation of hyperphosphorylated tau protein (NFTs), extracellular amyloid-beta $(A \beta)$ plaques (senile plaques) and neuronal loss [1]. Senile plaques are composed of a $4-\mathrm{kDa} \mathrm{A} \beta$ peptide derived from the cleavage of the amyloid precursor protein (APP) by two proteases, $\beta$ and $\gamma$ secretase [2]. The A $\beta$ peptide is thought to play a crucial role in the pathogenesis of AD. It adopts several neurotoxic forms including soluble and highly insoluble oligomers as well as proteolysis-resistant fibrils. The deposition of $A \beta$ is the result of an imbalance between $A \beta$ production and clearance; this imbalance leads to a situation of chronic inflammation in the brain. Amyloid deposition contributes to the activation of microglia, the principal innate immune cells of the central nervous system (CNS), and induces the production of a series of pro-inflammatory mediators such as cytokines and chemokines [3]. Here, we highlight the current understanding of the role of the neuroimmune system in $\mathrm{AD}$, with particular emphasis on the modulation of the immune system with immunotherapy as a potential disease-modifying treatment for $\mathrm{AD}$.

M.S. and R.B. contributed equally to this work.
C 2014 S. Karger AG, Basel

$1021-7401 / 14 / 0213-0079 \$ 39.50 / 0$
Maria Serpente

Neurology Unit, Department of Pathophysiology and Transplantation University of Milan, Fondazione Cà Granda, IRCCS Ospedale Maggiore Policlinico Via Francesco Sforza 35, IT-20122 Milan (Italy)

E-Mail maria.serpente@ unimi.it 


\section{The Role of the Immune System and Inflammation in AD}

Current evidence highlights that brain inflammation is a pathological hallmark of $\mathrm{AD}$. The inflammatory reaction is mediated by pro-inflammatory cytokines, and it was first hypothesized that a chronic and self-sustaining inflammatory interaction between activated microglia and astrocytes, stressed neurons and A $\beta$ plaques, occurs [4].

Activated cells produce not only pro-inflammatory cytokines but also chemokines, monocyte chemo-attractant proteins, macrophage inflammatory proteins, prostaglandins, leukotrienes, thromboxanes, coagulation factors, reactive oxygen species and other radicals, nitric oxide, complement factors, proteases, protease inhibitors and pentraxins $[5,6]$. In this context, $A \beta$ plaques and tangles stimulate a chronic inflammatory reaction, inducing the expression of pro-inflammatory cytokines in glia cells [7]. Inflammatory mediators released from activated microglia and astrocytes in turn enhance APP production and the amyloidogenic processing of APP to induce A $\beta$ 42 peptide production [7]. Therefore, many studies have provided evidence supporting the notion that inflammatory factors can contribute to neuronal dysfunction and cell death, either alone or along with other molecules. Cellular components of the brain which have many critical roles in the function of the brain and are involved in the inflammatory process in $\mathrm{AD}$ are microglia, astrocytes and, to a lesser extent, neurons.

\section{Microglia}

Microglia are the main cells of innate immunity of the CNS, acting as primary mediators of inflammation, which orchestrate the endogenous immune response. In healthy CNS tissue, microglia possess a ramified morphology with a round soma and numerous branching processes. Recent evidence indicates that ramified microglia have critical physiologic roles, including supporting and protecting neuron axonal growth, as well as synaptic remodeling in brain and spinal cord development. The contributions of microglia to CNS maturation can be attributed to their actions in the phagocytosis of cellular debris, release of a variety of cell signaling factors, including neurotrophins and extracellular matrix components, and direct contact with neurons $[8,9]$.

Microglia are rapidly activated by a number of pathologic events, including altered neuronal function, infections, traumatic injury, ischemia and inflammation. Activation results in a transition in microglial morphology to an ameboid state, which facilitates the migration of these cells to the site of damage [10]. Two different microglial phenotypes have been characterized under specific pro- and anti-inflammatory conditions. The M1 phenotype is induced by classic activation of microglia (e.g. by lipopolysaccharide) and is characterized by the production of predominantly pro-inflammatory cytokines such as interleukin (IL)-1, IL-6, tumor necrosis factor (TNF)- $\alpha$, interferon (IFN)- $\gamma$ and free radicals such as nitric oxide and superoxide anions. It plays a central role in the defense against pathogens and tumor cells, but can also damage healthy cells, such as neurons and glial cells. The alternative M2 anti-inflammatory phenotype can be subdivided in two different groups. One phenotype is hallmarked by arginase- 1 and induced by IL- 4 or IL-13, which downregulates inflammation and promotes tissue remodeling/repair and angiogenesis [11]. The second is a deactivated phenotype, is induced by IL-10 or tumor growth factor (TGF)- $\beta$, shows some increase in chemokine (C-C motif) receptor 2 and scavenger receptor expression and in phagocytic ability, but no increase in proinflammatory cytokine secretion [12].

Inflammatory changes are observed in the $\mathrm{AD}$ brain, particularly at the $A \beta$ deposits, which are rich in activated microglia. $A \beta$ contributes to enhance the inflammatory response by NFKB stimulation, a nuclear factor implicated in cytokine production [13], and also regulates the extracellular signal-regulated kinase and mitogen-activated protein kinase pathway that leads to the production of cytokines and chemokines [14]. These molecules contribute to further neuronal dysfunction and eventually death, together with complement components and free radicals [15]. It is important to note, however, that microglia are not the sole producers of cytokines following CNS insult. Astrocytes have also been implicated in the generation of pro-inflammatory mediators involved in neurodegenerative disorders [16].

\section{Astrocytes}

Astrocytes carry out many functions, such as regulation of synaptogenesis and angiogenesis, which promote neuronal survival and maturation [17]. In the AD brain, it has been shown that astrocytes are associated with $A \beta$ deposits, suggesting that these lesions generate chemotactic molecules that mediate astrocyte recruitment and activation. During the neuroinflammatory process of $\mathrm{AD}$, reactive astrocytes release and overproduce many different factors, including cytokines and chemokines $[18,19]$ such as $\beta$-subunit of $S 100$ protein, $S 100 \beta$, IL- $1 \beta$, IL-6, TNF- $\alpha$, IFN- $\gamma$-stimulated protein (IP) 10 and TGF- $\beta 2$, which could in turn induce the astrocytes reacDOI: $10.1159 / 000356529$
Serpente/Bonsi/Scarpini/Galimberti 
tivation [20]. These reactivated astrocytes could secret more inflammatory molecules to upregulate the APP mRNA and protein levels in neurons, thereby leading to an enhanced $A \beta$ generation from the APP on the neuronal membrane surface. Thus, $A \beta$, astrocytes, cytokines and neuronal APP could exert a vicious cycle in AD immunoneuropathology [16]. A $\beta$ could also be generated from astrocytes stimulated with pro-inflammatory molecules. It has been demonstrated that IFN- $\gamma$ in combination with TNF- $\alpha$ or IL- $1 \beta$ could induce primary human astrocytes or astrocytoma cells to produce $A \beta$ [21].

During the early stage of $\mathrm{AD}, \mathrm{A} \beta$-triggered activated astrocytes, rather than microglia activation, initiate a neuroinflammatory cascade in which the pro-inflammatory cytokines and chemokines have autocrine and paracrine effects through interactions between astrocytes, neurons and microglia [22]. Thus, the $A \beta$-reactivated astrocytes might contribute substantially to cytokine-mediated inflammation in early $\mathrm{AD}$ pathogenesis.

\section{Neurons}

Neurons seem to play a role in the inflammatory process of $\mathrm{AD}$ and have been implicated in the production of inflammatory products. Neurons are able to produce several cytokines, such as IL-1 [23], IL-6 [24] and TNF- $\alpha$ [25]. The neuron production of these pro-inflammatory products may trigger further inflammatory processes that worsen the environment and lead to neuronal toxicity and death [5].

\section{Cytokines}

Cytokines are signaling molecules, responsible for the cross-talk between cells of the immune system and neuroendocrine system. They are produced by macrophages and lymphocytes, as well as by microglia and astrocytes in the CNS. Cytokines are commonly classified in two categories: pro-inflammatory cytokines such as IL-1, TNF- $\alpha$, IFN- $\gamma$, IL-12, IL-18, granulocyte-macrophage colonystimulating factor and anti-inflammatory cytokines such as IL-4, IL-10, IL-13, IFN- $\alpha$ and TGF- $\beta$. This classification depends on their biological activities: if cytokines promote inflammation they are called pro-inflammatory cytokines, otherwise if they suppress the activity of pro-inflammatory cytokines they are called anti-inflammatory cytokines. The biological effects induced by cytokines include cell growth and differentiation, the stimulation or inhibition of cell proliferation, cytotoxicity/apoptosis, antiviral activity, inflammatory responses and upregulation of the expression of surface membrane proteins.

Innate Immune System and Inflammation in AD: Pathogenesis to Treatment
Several cytokines are produced by neurons or glia and there are a number of reports indicating changes in their levels in the $\mathrm{AD}$ brain, blood and cerebrospinal fluid (CSF). Levels of IL- $1 \alpha$, IL-1 $\beta$, IL-6, TNF- $\alpha$, granulocytemacrophage colony-stimulating factor, the type B of IL-8 receptor and the receptor for CSF-1 are increased in $\mathrm{AD}$ brain tissue [26, 27].

Recently, it has become clear that there are many interactions between cytokines and components of the AD senile plaques. In particular, cytokines can stimulate secretion of a number of the other proteins found in senile plaques [27] and they may interact with A $\beta$. IL-1, for example, regulates APP processing and $\mathrm{A} \beta$ production in vitro [28]. In turn, fibrillar $A \beta$ has been affirmed to increase neurotoxic secretory products, pro-inflammatory cytokines and reactive oxygen species [29]. During inflammation, the pro-inflammatory cytokines are secreted by microglia and astrocytes surrounding $A \beta$ neuritic plaques, inducing microglial activation, astrogliosis, and further secretion of pro-inflammatory molecules and amyloids, thus regulating the intensity and duration of the immune response [5].

As previously pointed out, the classical pro-inflammatory cytokines involved in neurodegeneration are IL-1, IL- 6 and TNF- $\alpha$. The IL-1 family of cytokines includes IL- $1 \alpha$ and IL- $1 \beta$, which trigger cell activation upon binding with specific membrane receptors. IL-1 is an immunoregulatory cytokine that is overexpressed within affected cerebral cortical regions of the $\mathrm{AD}$ brain and carries out many functions, such as enhancing neuronal acetylcholinesterase activity, microglial and astrocyte activation, and induction of $S 100 \beta$ overexpression by reactive astrocytes [30]. The early overexpression of IL-1 in AD has led to the suggestion that it plays a key role in plaque evolution. In particular, IL-1 promotes the synthesis [31] and processing of APP and may therefore promote further amyloid production and deposition in plaques.

IL-6 is a pleiotropic cytokine strongly induced under pathological conditions and its detrimental effect is associated with several CNS disorders. On the other hand, IL-6 may also have anti-inflammatory and immunosuppressive properties; in fact it regulates neuronal survival [32], promotes astrogliosis [33] and activates microglia [34]. All the cells involved in the inflammatory process in AD seem capable of synthesizing IL-6 [35].

TNF- $\alpha$ plays a central role in initiating and regulating the cytokine cascade during inflammatory or disease states. Glial cells secrete TNF- $\alpha$ in response to pathological stimuli, which activate apoptosis, cytotoxicity and immune activation [36]. By contrast, TNF- $\alpha$ has been re-

Neuroimmunomodulation 2014;21:79-87 
ported to play a trophic or protective role in neuronal survival [6] in the AD brain.

Taking into account cytokine levels in CSF, which is thought to be the biological fluid that best reflects the ongoing brain pathology, IL-11 was found to be significantly increased in $\mathrm{AD}$ subjects as compared to controls, whereas IL-6 mean levels did not differ between patients and controls. The highest peaks were observed in patients with a less severe degree of cognitive deterioration, therefore suggesting a role of IL-11 in the early phases of neurodegeneration [37].

\section{Chemokines}

The chemokines family consists of over 50 different molecules that induce chemotaxis, tissue extravasation and modulation of leukocyte function during inflammation [38]. Recent studies have focused on understanding the role of chemokines and their receptors in $\mathrm{AD}$, since they have been found to be upregulated in resident CNS cells in the AD brain [39]. It is likely that chemokines, produced by senile plaques, play an important role in recruiting microglia and astrocytes to the site of $A \beta$ deposition. In vitro studies have demonstrated the ability of $A \beta$ to stimulate the production of IL-8, IP10, monocyte chemo-attractant protein-1, macrophage inflammatory protein (MIP)- $1 \alpha$ and MIP- $1 \beta$ from human monocytes and microglia cultured from rapid autopsies of AD [40]. Furthermore, in reactive astrocytes MIP-1 $\alpha$ has been detected nearby plaque-associated inflammation and neurodegeneration [41].

Chemokines are also altered in CSF from patients compared with controls. Galimberti et al. [42] demonstrated that IP 10 concentration was elevated in CSF from patients with $\mathrm{MCI}$ and mild impaired $\mathrm{AD}$, but not in patients with $\mathrm{AD}$ with a severe cognitive decline and positively correlated with the Mini Mental State Examination score. Conversely, monocyte chemo-attractant protein-1 and IL-8 levels were significantly increased in all individuals with cognitive impairment as compared with agematched healthy controls.

\section{Current and Future Treatments for AD}

To date, anticholinesterase inhibitors and memantine are used to manage cognitive and behavioral symptoms of $\mathrm{AD}$, but the effects of these treatments are limited and they do not avoid the progression of the disease [43]. The demonstration of an inflammatory role in the pathogenesis of $\mathrm{AD}$, and the observation that nonsteroidal antiinflammatory drugs protect against the development of $\mathrm{AD}$ [44], has led to the development of clinical trials with anti-inflammatory drugs as a treatment option for patients with AD. Nevertheless, despite these premises, in prospective studies all drugs tested failed to slow the progression of cognitive decline in patients with mild-tomoderate $\mathrm{AD}$. Thus, nonsteroidal anti-inflammatory drugs are no longer considered to be viable treatment options for $\mathrm{AD}$ patients, as well as other approaches targeting oxidative damage, metals, etc. [see 45 for review].

The recent additional advances in the identification of biomolecular mechanisms and biomarkers for $\mathrm{AD}$ has led to the concept that novel treatments should modify disease pathogenic mechanisms in early phases (before the occurrence of full dementia). Since the deposition of $A \beta$ is the key event in $\mathrm{AD}$ pathogenesis, many new therapeutic approaches aim to inhibit $A \beta$ production or aggregation and to clear $A \beta$ from the brain [46]. Among the various strategies to influence $A \beta$ deposition, immunotherapy is the most studied disease-modifying approach.

\section{Harnessing the Immune System to Cure AD: Vaccination}

Active immunization implies the administration of synthetic intact $A \beta$ peptide or fragments of $A \beta$ conjugated to a carrier protein, leading to the production of specific antibodies. An alternative approach of immunotherapy involves passive administration of monoclonal anti-A $\beta$ antibodies which produce an immune response without requiring a pro-inflammatory $\mathrm{T}$ cell reaction [47].

\section{Knowledge Gained from Preclinical Studies}

The first evidence indicating that the use of antibodies could be a potential therapeutic approach was reported in 1996 by Solomon et al. [48], who observed in vitro that antibodies directed against the $\mathrm{N}$-terminal amino acids of A $\beta$ peptide inhibited the formation of amyloid fibrils. Then, in 1999, Schenk et al. [49] demonstrated that active immunization with $\mathrm{A} \beta$ in young PDAPP transgenic mice overexpressing the APP gene prevented the formation of senile plaques, neuritic dystrophy and astrogliosis, and removed the preformed lesions in older mice. Further studies confirmed these results and showed that removal of plaques was also associated with an improvement in learning and memory tasks [50]. In parallel with the ac-
Serpente/Bonsi/Scarpini/Galimberti 
tive immunization, Bard et al. [51] demonstrated for the first time the possible important role of passive immunization; this study established that the peripheral injection of anti-A $\beta$ monoclonal antibodies reduced the $A \beta$ load by up to $86 \%$ in the brains of $\mathrm{AD}$ transgenic mice. Plaque clearance was shown to occur through fragment crystallizable $(\mathrm{Fc})$ receptor-mediated phagocytosis by microglial cells, with no evidence of $\mathrm{T}$ cell response activation [51].

Other studies have demonstrated that Fc receptor interactions are not necessarily required for $A \beta$ removal [52], suggesting that other mechanisms may also be involved in the $\mathrm{A} \beta$ clearance with active and passive immunotherapy. One of these proposed mechanisms of action is called peripheral sink, and thanks to this mechanism the formation of antigen-antibody complexes in the periphery allows the sequestration of amyloid away from the brain and prevents the deposition of new plaques. The third hypothesis proposes that the formation of antigenantibody complexes alters the conformation of $A \beta$ molecules, decreasing the chance of senile plaques forming [47]. Following these promising results immunotherapy was rapidly translated into the clinic.

\section{Active Immunotherapy: Clinical Trials and Future \\ Directions}

Given the promising preclinical results described above, AN1792, a synthetic A $\beta$ peptide, was the first vaccine tested in clinical trials [53]. A phase I controlled study was started in a cohort of 80 subjects with mild-tomoderate AD. Of all the subjects who received AN1792, $53 \%$ developed a positive anti-AN1792 antibody response at one or more points during the trials. In 2001, a multicenter, randomized, placebo-controlled, phase II doubleblind clinical trial was started in a cohort of $300 \mathrm{AD}$ patients. Although the adverse events reported during the initial study were either mild or moderate in nature, $6 \%$ of all patients who received active therapy developed aseptic meningoencephalitis. The trial was halted after $2-3$ injections. At the time of suspension of dosing due to meningoencephalitis, over $90 \%$ of patients had received 2 of the planned 6 injections of AN1792/placebo. The study has been modified to allow safety follow-up for at least 9 months after the last injection. Despite the limited number of administrations, $20 \%$ of the patients treated with AN1792 were classified as antibody responders [54]. The final results of the trial were published in 2005 [53].

In 2006 Nicoll et al. [54] presented the neuropathological findings of patients who had received 2 -5 doses of AN1792. A marked reduction in senile plaque deposition

Innate Immune System and Inflammation in AD: Pathogenesis to Treatment was noted in the temporal cortex of patients that had developed anti-A $\beta$ antibodies. Subsequently, additional studies confirmed these data; in particular, Holmes et al. [55] published long-term findings of AN1792-treated subjects up to 5 years after the last injection of the vaccine. Despite the observation of plaque removal, immunization had no effect on long-term survival or clinical outcomes.

Based on the hypothesis that the use of full-length amyloid peptide in AN1792 could have resulted in T cell autoimmune response that caused the meningeal inflammation, subsequent efforts have focused on secondgeneration amyloid vaccine design. The aim was to promote the humoral and not a cellular immune response [56]. The first second-generation vaccine tested in $\mathrm{AD}$ patients was CAD106, which is composed of the $A \beta$ amyloid 1-6 peptide coupled with $Q \beta$ carrier. The $A \beta 1-6$ peptide derives from the N-terminal B cell epitope of $A \beta$ that avoids $\mathrm{T}$ cell activation. Administration of CAD106 to APP transgenic mice showed a reduction of $A \beta$ accumulation in the brain. A 52-week study with CAD106 included 58 patients with mild-to-moderate AD in 2 cohorts. Injection-site erythema was the most frequent side effect observed, but nasopharyngitis was also reported. No clinical or subclinical cases of meningoencephalitis were observed. CAD106 was associated with an $A \beta$ antibody response in 16 out of 24 patients in cohort 1 and 18 out of 22 patients in cohort 2 . The data reported from this trial suggest that CAD106 has a favorable safety profile and acceptable antibody response in $\mathrm{AD}$ patients. To date other vaccines are under clinical investigation, such as ACI-24, Affitope AD-02, Affitope AD-03, ACC-001, UB-311 and V-950 [see 56 for review].

\section{Passive Immunotherapy: Clinical Trials and Future Directions}

Passive immunotherapeutic approaches are being investigated in parallel with active therapies due to serious side effects of active immunization. The direct administration of monoclonal antibodies against $\mathrm{A} \beta$ has been trailed in humans. This approach is an alternative solution to avoid an undesirable $\mathrm{T}$ cell-induced inflammation and it is theoretically safer and offers more control over the active immunotherapy. Despite significant side effects such as cerebral amyloid angiopathy observed with this approach [57], at least 11 passive immunotherapy trials are currently ongoing.

Neuroimmunomodulation 2014;21:79-87 
Two humanized monoclonal antibodies have been initially developed: bapineuzumab (clone 3D6), directed against the $\mathrm{N}$-terminal region of $\mathrm{A} \beta$ peptide [58], and solanezumab (clone $\mathrm{m} 266$ ), directed against $\mathrm{A} \beta$ central region [59]. Antibodies against the $\mathrm{N}$-terminal region can recognize all $A \beta$ structural forms (monomers, oligomers and fibrils) as well as the APP, suggesting that this epitope is always exposed during $A \beta$ fibrillogenesis [60]. Bapineuzumab is the prototypal anti-A $\beta$ N-terminus antibody that displays anti-aggregating properties in vitro and in vivo [48]. Prior to the completion of the phase II study, a phase III trial with bapineuzumab was initiated. The results of these trials did not show overall efficacy but a small subset of patients, i.e. the ApoE noncarriers who received the second lowest of the four doses six times, had responded well by 78 weeks. Subsequent trials in noncarriers were negative and 2 trials in ApoE4 carriers were initiated but then discontinued due to a lack of effect [58].

Antibodies against the central region of $A \beta$ only bind monomers and do not enter the CNS. It was observed that these antibodies act via a peripheral sink mechanism. The best characterized antibody direct to the $\mathrm{A} \beta$ central region is solanezumab, which provides an increase of plasma $A \beta$ in treated patients. Two large phase II trials have been conducted with solanezumab. In the first, a significant reduction in cognitive decline (42\%) in mild AD was observed, but results were not replicated in the second trial [59]. There are also antibodies directed against the A $\beta$ C-terminal region, but their mechanism of action is not yet fully understood. Wilcock et al. [61] have designed a deglycosylated version of an anti-C-terminal antibody (2H6 clone) to avoid the side effects observed, including cerebral amyloid angiopathy. The humanized version of $2 \mathrm{H} 6$, ponezumab, is now in phase II clinical trials [see 56 for a review]. Several studies in vivo have shown that the use of modified antibodies significantly increases the removal of plaques in the brain and the reduction in the severity of side effects [62]. Consequently, engineered antibodies have emerged as a promising alternative to treat $\mathrm{AD}$ [63]. There are several types of modified antibodies, versatile molecules that can be genetically engineered to produce various formats, such as fragment antigen binding, single-chain antibodies (scFvs), $\mathrm{V}$-domain and bispecific antibodies. The smaller fragments retain the specificity and often affinity of the parental antibody but display different pharmacokinetic and biochemical characteristics compared to the larger IgG format. Moreover, their low molecular weight is predicted to facilitate their passage across the blood-brain barrier [64]. Therefore, current efforts are now focusing on improving the safety and tolerability of passive immunotherapy by using recombinant antibody fragments or Fc-engineered antibodies, which lack effector functions and are less prone to triggering deleterious side effects.

Natural anti-amyloid antibodies have been found in human intravenous immunoglobulins (IVIg) obtained from the pooled plasma of healthy blood donors. In 2010, Magga et al. [65] showed that in the mouse brain the IVIg, administrated at the peripheral level, penetrated the blood-brain barrier and bound to $A \beta$ fibrils. Two phase I studies have been carried out in the last few years (www. alzforum.org), showing cognitive stabilization or even a slight ADAS-cog improvement.

However, in 2013, Dodel et al. [66] published the largest completed trial assessing IVIg in AD patients. The authors, in accordance with previous studies, suggested that IVIg have acceptable safety profiles, but have no effects on cognition.

\section{An Alternative Approach: Tau Immunotherapy}

The most advanced alternative hypothesis of $\mathrm{AD}$, in addition to amyloid causality, is tau hyperphosphorylation. Tau phosphorylation leads to its dissociation from microtubules within the cells and to the formation of neurotoxic neurotrophic factors. $A \beta$ immunotherapy results in a very limited indirect clearance of tau aggregates in dystrophic neuritis, showing the importance of developing parallel and specific immunotherapeutic approaches directed against pathological tau protein [67]. Vaccination approaches have been considered, but the development of a successful therapy is complicated by the fact that tau protein is intracellular. The first attempt to use full-length human recombinant tau in its unphosphorylated form for immunization of wild-type mice caused tau pathology, astrogliosis and encephalomyelitis. This effect was probably due to the size of the immunogen [68]. Subsequently, in tangle mouse models, both active and passive immunization with tau peptides phosphorylated at serine 396 and 404 (FITC-tau $379-408$ ) or tau antibody, reduced tau pathology and prevented cognitive impairment $[69,70]$.

\section{Concluding Remarks}

More than 100 years after its first description, AD remains the most frequent and studied neurodegenerative disease. The results obtained in the last few years have 
better clarified some genetic and molecular aspects of the basis of $\mathrm{AD}$, including the role of genes, the inflammatory factors mainly involved in the pathology and brain immune cells that play a critical role in $\mathrm{AD}$ pathogenesis, microglia and astrocytes. In early stages of $\mathrm{AD}$, microglia is activated in response to the formation of amyloid plaques and vice versa. In the areas of heavy $A \beta$ concentration in the CNS of $\mathrm{AD}$ patients, microglia are able to phagocytose and degrade $A \beta$, exerting their neuroprotective properties, but, at the same time, they are also capable of producing many pro-inflammatory factors including cytokines and chemokines. During the progression of disease, an increase in $A \beta$ production occurs, as well as an inadequate $A \beta$ clearance and continued production of neurotoxic inflammatory products that contribute to neurodegeneration. For all these reasons the therapeutic approaches that inhibit $A \beta$ production and aggregation or, alternatively, clear $A \beta$ from the brain, are the most attractive. In this framework, the immunotherapy, active and passive, is the most studied and promising approach. The initial attempts to translate the successful preclinical results into safe and effective $\mathrm{AD}$ therapies have led to the development of serious and severe side effects in some patients. Furthermore, large phase III trials with vaccines or passive immunization failed to demonstrate any effect on cognition, therefore suggesting that targeting only the $\mathrm{A} \beta$ cascade may not represent the 'cure' for $\mathrm{AD}$, as there are other mechanisms implicated in the pathophysiology of the disease. For instance, $A \beta$ lesions are not associated with clinical symptoms and the total amyloid load remains stable through clinical stages of the disease, even if there is a progressive cognitive and functional impairment, whereas tau pathology seems to be much more related to the clinical presentation and to the progression of the disease [71].

For the future, the new generation of immunotherapies will have to show a major ability to clear $A \beta$ and an acceptable safety profile. In addition, biomarkers should be used to select patients to be included in clinical trials in order to exclude the recruitment of patients with non$\mathrm{AD}$ dementia. Moreover, the removal of plaques could be not sufficient to halt the disease progression because the neuronal loss is too consistent in the time of the start of therapy. Therefore, clinical trials should be carried out as early as possible during the course of the disease with the hope that targeting $A \beta$ earlier in the disease process will provide better clinical outcomes.

\section{References}

1 Selkoe DJ: Translating cell biology into therapeutic advances in Alzheimer's disease. $\mathrm{Na}$ ture 1999;399:A23-A31.

-2 Kang J, Lemaire HG, Unterbeck A, Salbaum JM, Masters CL, Grzeschik KH, Multhaup G, Beyreuther K, Müller-Hill B: The precursor of Alzheimer's disease amyloid A4 protein resembles a cell-surface receptor. Nature 1987; 325:733-736

3 Robert R, Wark KL: Engeneered antibody approaches for Alzheimer's disease immunotherapy. Arch Biochem Biophys 2012;132138.

4 Finch CE, Morgan TE: Systemic inflammation, infection, ApoE alleles, and Alzheimer disease: a position paper. Curr Alzheimer Res 2007;4:185-189.

5 Tuppo EE, Arias HR: The role of inflammation in Alzheimer's disease. Int J Biochem Cell Biol 2005;37:289-305.

6 Akiyama H, Barger S, Barnum S, et al: Inflammation and Alzheimer's disease. Neurobiol Aging 2000;21:383-421.

-7 Atwood CS, Obrenovich ME, Liu T, Chan H, Perry G, Smith MA, Martins RN: Amyloid- $\beta$ : a chameleon walking in two worlds: a review of the trophic and toxic properties of amyloid- $\beta$. Brain Res Rev 2003;43:1-16.
8 Bessis A, Bechade C, Bernard D, Roumier A: Microglial control of neuronal death and synaptic properties. Glia 2007;55:233-238.

-9 Kettenmann $\mathrm{H}$, Hanisch UK, Noda $M$, Verkhratsky A: Physiology of microglia. Physiol Rev 2011;91:461-553.

10 Dheen ST, Kaur C, Ling EA: Microglial activation and its implications in the brain diseases. Curr Med Chem 2007;14:1189-1197.

11 Czeh M, Gressens P, Kaindl AM: The yin and yang of microglia. Dev Neurosci 2011;33: 199-209.

12 Pickford F, Marcus J, Camargo LM, Xiao Q, Graham D, Mo J, Burkhardt M, Kulkarni V, Crispino J, Hering H, Hutton H: Progranulin is a chemoattractant for microglia and stimulates their endocytic activity. Am J Pathol 2011;178:284-295.

13 Combs CK, Karlo JC, Kao SC, Landreth GE: $\beta$-Amyloid stimulation of microglia anti monocytes results in TNFa-dependent expression of inducible nitric oxide synthase and neuronal apoptosis. J Neurosci 2001;21: 1179-1188.

14 Ho GJ, Drego R, Hakimian E, Masliah E: Mechanisms of cell signaling and inflammation in Alzheimer's disease. Curr Drug Targets Inflamm Allergy 2005;4:247-256.
15 Verri M, Pastoris O, Dossena M, Aquilani R, Guerriero F, Cuzzoni G, Venturini L, Ricevuti G, Bongiorno AI: Mitochondrial alterations, oxidative stress and neuroinflammation in Alzheimer's disease. Int J Immunopathol Pharmacol 2012;25:345-353.

16 Li C, Zhao R, Gao K, Wei Z, Yin MY, Lau LT, Chui D, Hoi Yu AC: Astrocytes: implications for neuroinflammatory pathogenesis of $\mathrm{Alz}$ heimer's disease. Curr Alzheimer Res 2011;8: 67-80.

17 Schousboe A, Westergaard N, Sonnerwald U, Petersen SB, Yu AC, L: Hertz: Regulatory role of astrocytes for neuronal biosynthesis and homeostasis of glutamate and GABA. Prog Brain Res 1992;94:199-211.

18 Aloisi F: Cytokine production; in Kettnman H, Ransom B (eds): Neuroglia. Oxford, Oxford University, 2005, pp 285-301.

-19 Strack A, Asensio VC, Campbell IL, Schluter $\mathrm{D}$, Deckert M: Chemokines are differentially expressed by astrocytes, microglia and inflammatory leukocytes in Toxoplasma encephalitis and critically regulated by interferon- $\gamma$. Acta Neuropathol 2002;103: 458-468.
Innate Immune System and Inflammation in AD: Pathogenesis to Treatment
Neuroimmunomodulation 2014;21:79-87 DOI: $10.1159 / 000356529$ 
20 Maccioni RB, Rojo LE, Fernandez JA, Kuljis RO: The role of neuroimmunomodulation in Alzheimer's disease. Ann N Y Acad Sci 2009; 1153:240-246.

-21 Blasko I, Veerhuis R, Stampfer-Kountchev M, Saurwein-Teissl M, Eikelenboom P, Grubeck-Loebenstein B: Costimulatory effects of interferon $-\gamma$ and interleukin- $1 \beta$ or tumor necrosis factor- $\alpha$ on the synthesis of $A \beta 1-40$ and A $\beta 1-42$ by human astrocytes. Neurobiol Dis 2000;7:682-689.

22 White JA, Manelli AM, Holmberg KH, Van Eldik LJ, Ladu MJ: Differential effects of oligomeric and fibrillar amyloid- $\beta 1-42$ on astrocyte-mediated inflammation. Neurobiol Dis 2005; 18:459-465.

-23 Friedman WJ: Cytokines regulate expression of the type 1 interleuken- 1 receptor in rat hippocampal neurons and glia. Exp Neurol 2001; 168:23-31.

-24 Li Y, Barger SW, Liu L, Mrak RE, Griffin WST: S100- $\beta$ induction of the pro-inflammatory cytokine interleukin-6 in neurons: implications for Alzheimer pathogenesis. J Neurochem 2000;74:143-150.

25 Renauld AE, Spengler RN: Tumor necrosis factor expressed by primary hippocampal neurons SH-SY5Y cells is regulated by $a_{2}$ adrenergic receptor activation. J Neurosci Res 2002;67:264-274.

26 Walker D, McGeer E, McGeer P: Involvement of inflammation and complement in Alzheimer's disease: Clinical Neuroimmunology. Oxford, Blackwell Scientific, 1997, pp 172188.

27 McGeer E, McGeer P: Inflammatory cytokines in the CNS. CNS Drugs 1997;7:214287.

28 Blasko I, Marx F, Steiner E, Hartmann T, Grubeck-Loebenstein B: TNF $\alpha$ plus IFN $\gamma$ induce the production of Alzheimer $\beta$-amyloid peptides and decrease the secretion of APPs. FASEB J 1999;13:63-68.

-29 Eikelenboom P, Van Gool WA: Neuroinflammatory perspectives on the two faces of Alzheimer's disease. J Neural Transm 2004;111: 281-294.

30 Mrak RE, Griffin WST: Interleukin-1, neuroinflammation, and Alzheimer's disease. Neurobiol Aging 2001;22:903-908.

-31 Mackenzie IR: Anti-inflammatory drugs and Alzheimer type pathologyin aging. Neurology 2000;54:732-734.

32 Benveniste EN: Cytokine actions in the central nervous system. Cytokine Growth Factor Rev 1998;9:259-275.

-33 Selmaj KW, Farooq M, Norton WT, Raine CS, Brosnan CF: Proliferation of astrocytes in vitro in response to cytokines: a primary role for tumor necrosis factor. J Immunol 1990;144 129-135.

34 Heyser CJ, Masliah E, Samimi A, Campbell IL, Gold LH: Progressive decline in avoidance learning paralleled by inflammatory neurodegeneration in transgenic mice expressing interleukin 6 in the brain. Proc Natl Acad Sci USA 1997;94:1500-1505.
35 Van Wagoner NJ, Oh JW, Repovic P, Benveniste EN: IL-6 (IL-6) production by astrocytes: autocrine regulation by IL- 6 and the soluble IL-6 receptor. J Neurosci 1999;19: 5236-5244.

36 Smith JA, Das A, Ray SK, Banik NL: Role of pro-inflammatory cytokines released from microglia in neurodegenerative diseases. Brain Res Bull 2012;87:10-20.

37 Galimberti D, Venturelli E, Fenoglio C, Guidi I, Villa C, Bergamaschini L, Cortini F, Scalabrini D, Baron P, Vergani C, Bresolin N, Scarpini E: Intrathecal levels of IL-6, IL-11 and LIF in Alzheimer's disease and frontotemporal lobar degeneration. J Neurol 2008; 255:539-544.

38 Owens T, Babcock AA, Millward JM, ToftHansen H: Cytokine and chemokine interregulation in the inflamed or injured CNS. Brain Res Rev 2005;48:178-184.

39 Xia M, Hyman BT: Chemokines/chemokine receptors in the central nervous system and Alzheimer's disease. J Neurovirol 1999;5:3241.

-40 Lue LF, Rydel RE, Brigham EF, Yang LB, Hampel H, Murphy GM, Brachova L, Yan SD, Walker DG, Shen Y, Rogers J: Inflammatory repertoire of Alzheimer's disease and nondemented elderly microglia in vitro. Glia 2001; 35:72-79.

41 Xia MQ, Qin SX, Wu LJ, Mackay CR, Hyman BT: Immunohistochemical study of the $\beta$-chemokine receptors CCR3 and CCR5 and their ligands in normal and Alzheimer's disease brains. Am J Pathol 1998;153:31-37.

42 Galimberti D, Schoonenboom N, Scheltens P, Fenoglio C, Bouwman F, Venturelli E, Guidi I, Blankenstein MA, Bresolin N, Scarpini E: Intrathecal chemokine synthesis in mild cognitive impairment and Alzheimer disease. Arch Neurol 2006;63:538-543.

43 Delrieu J, Piau A, Caillaud C, Voisin T, Vellas $B$ : Managing cognitive dysfunction through the continuum of Alzheimer's disease: role of pharmacotherapy. CNS Drugs 2011;25:213226.

-44 McGeer PL, Schulzer M, McGeer EG: Arthritis and anti-inflammatory agents as possible protective factors for Alzheimer's disease: a review of 17 epidemiologic studies. Neurology 1996;47:425-432.

45 Galimberti D, Scarpini E: Progress in Alzheimer's disease. J Neurol 2012;259:201-211.

$46 \mathrm{Fu} \mathrm{HJ}$, Liu B, Frost JL, Lemere CA: Amyloid- $\beta$ immunotherapy for Alzheimer's disease. CNS Neurol Disord Drug Targets 2010;9: 197-206.

47 Morgan D: Immunotherapy for Alzheimer's disease. J Alzheimer Dis 2006;9:425-432.

48 Solomon B, Koppel R, Hanan E, Katzav T: Monoclonal antibodies inhibit in vitro fibrillar aggregation of the Alzheimer $\beta$-amyloid peptide. Proc Natl Acad Sci USA 1996;93: 452-455.
49 Schenk D, Barbour R, Dunn W, Gordon G, Grajeda H, Guido T, Hu K, Huang J, JohnsonWood K, Khan K, Kholodenko D, Lee M, Liao Z, Lieberburg I, Motter R, Mutter L, Soriano F, Shopp G, Vasquez N, Vandevert C, Walker S, Wogulis M, Yednock T, Games D, Seubert P: Immunization with amyloid- $\beta$ attenuates Alzheimer-disease-like pathology in the PDAPP mouse. Nature 1999;400:173-177.

50 Janus C, Pearson J, McLaurin J, Mathews PM, Jiang Y, Schmidt SD, Chishti MA, Horne P, Heslin D, French J, Mount HT, Nixon RA, Mercken $M$, Bergeron C, Fraser PE, St George-Hyslop P, Westaway D: A $\beta$ peptide immunization reduces behavioural impairment and plaques in a model of Alzheimer's disease. Nature 2000;408:979-982.

51 Bard F, Cannon C, Barbour R, Burke RL, Games D, Grajeda H, Guido T, Hu K, Huang J, Johnson-Wood K, Khan K, Kholodenko D, Lee M, Lieberburg I, Motter R, Nguyen M, Soriano F, Vasquez N, Weiss K, Welch B, Seubert P, Schenk D, Yednock T: Peripherally administered antibodies against amyloid $\beta$-peptide enter the central nervous system and reduce pathology in a mouse model of Alzheimer disease. Nat Med 2000;6:916-919.

52 Lobello K, Ryan MJ, Liu E, Rippon G, Black R: Targeting beta amyloid: a clinical review of immunotherapic approaches in Alzheimer's disease. Int J Alzheimers Dis 2012;2012: 628070.

53 Bayer AJ, Bullock R, Jones RW, Wilkinson D, Paterson KR, Jenkins L, Millais SB, Donoghue $S$ : Evaluation of the safety and immunogenicity of synthetic A $\beta 42$ (AN1792) in patients with AD. Neurology 2005;64:94-101.

-54 Nicoll JA, Barton E, Boche D, Neal JW, Ferrer I, Thompson P, Vlachouli C, Wilkinson D, Bayer A, Games D, Seubert P, Schenk D, Holmes C: $A \beta$ species removal after a $\beta 42$ immunization. J Neuropathol Exp Neurol 2006; 65:1040-1048.

55 Holmes C, Boche D, Wilkinson D, Yadegarfar G, Hopkins V, Bayer A, Jones RW, Bullock R, Love S, Neal JW, Zotova E, Nicoll JA: Longterm effects of $A \beta 42$ immunisation in Alzheimer's disease: follow-up of a randomised, placebo-controlled phase I trial. Lancet 2008; 372:216-223.

56 Galimberti D, Ghezzi L, Scarpini E: Immunotherapy against amyloid pathology in Alzheimer's disease. J Neurol Sci 2013;333:5054.

57 Pfeifer M, Boncristiano S, Bondolfi L, Stalder A, Deller T, Staufenbiel M, Mathews PM, Jucker M: Cerebral hemorrhage after passive anti-A $\beta$ immunotherapy. Science 2002;298: 1379.

58 Kerchner GA, Boxer AL: Bapineuzumab. Expert Opin Biol Ther 2010;10:1121-1130.

59 Samadi H, Sultzer D: Solanezumab for Alzheimer's disease. Expert Opin Biol Ther 2011; 11:787-798. 
60 Robert R, Lefranc MP, Ghochikyan A, Agadjanyan MG, Cribbs DH, Van Nostrand WE, Wark KL, Dolezal O: Restricted V gene usage and $\mathrm{VH} / \mathrm{VL}$ pairing of mouse humoral response against the $\mathrm{N}$-terminal immunodominant epitope of the amyloid $\beta$ peptide. Mol Immunol 2010;48:59-72.

61 Wilcock DM, Alamed J, Gottschall PE, Grimm J, Rosenthal A, Pons J, Ronan V, Symmonds K, Gordon MN, Morgan D: Deglycosylated anti-amyloid-beta antibodies eliminate cognitive deficits and reduce parenchymal amyloid with minimal vascular consequences in aged amyloid precursor protein transgenic mice. J Neurosci 2006;26: 5340-5346.

62 Das P, Howard V, Loosbrock N, Dickson D, Murphy MP, Golde TE: Amyloid- $\beta$ immunization effectively reduces amyloid deposition in $\mathrm{FcR} \gamma^{-/-}$knock-out mice. J Neurosci 2003; 23:8532-8538.

63 Wang YJ, Zhou HD, Zhou XF: Modified immunotherapies against Alzheimer's disease: toward safer and effective amyloid clearance. J Alzheimers Dis 2010;21:1065-1075.
64 Robert R, Wark KL: Engineered antibody approaches for Alzheimer's disease immunotherapy. Arch Biochem Biophys 2012;526: 132-138.

65 Magga J, Puli L, Pihlaja R, Kanninen K, Neulamaa S, Malm T, Härtig W, Grosche J, Goldsteins G, Tanila H, Koistinaho J, Koistinaho M: Human intravenous immunoglobulin provides protection against $A \beta$ toxicity by multiple mechanisms in a mouse model of Alzheimer's disease. J Neuroinflammation 2010;7;7:90.

66 Dodel R, Rominger A, Bartenstein P, Barkhof F, Blennow K, Förster S, Winter Y, Bach JP, Popp J, Alferink J, Wiltfang J, Buerger K, Otto M, Antuono P, Jacoby M, Richter R, Stevens J, Melamed I, Goldstein J, Haag S, Wietek S, Farlow M, Jessen F: Intravenous immunoglobulin for treatment of mild-to-moderate Alzheimer's disease: a phase 2, randomised, double-blind, placebo-controlled, dose-finding trial. Lancet Neurol 2013;12:233-243.
67 Himmelstein DS, Ward SM, Lancia JK, Patterson KR, Binder LI: Tau as a therapeutic target in neurodegenerative disease. Pharmacol Ther 2012;136:8-22 Review.

68 Rosenmann H, Grigoriadis N, Karussis D, Boimel M, Touloumi O, Ovadia H, Abramsky O: Tauopathy-like abnormalities and neurologic deficits in mice immunized with neuronal tau protein. Arch Neurol 2006;63:14591467.

69 Boutajangout A, Quartermain D, Sigurdsson EM: Immunotherapy targeting pathological tau prevents cognitive decline in a new tangle mouse model. J Neurosci 2010;30:1655916566.

70 Chai X, Wu S, Murray TK, Kinley R, Cella CV, Sims H, Buckner N, Hanmer J, Davies P, O’Neill MJ, Hutton ML, Citron M: Passive immunization with anti-Tau antibodies in two transgenic models: reduction of Tau pathology and delay of disease progression. J Biol Chem 2011;286:34457-34467.

71 Hyman BT: Amyloid-dependent and amyloid-independent stages of Alzheimer disease. Arch Neurol 2011;68:1062-1064. 